\title{
Promises and Challenges of Density Functional Theory in $\mathrm{CO}_{2}$ Reduction
}

\author{
Jenbrie M. Kessete, ${ }^{a}$ Taye B. Demissie, ${ }^{*, a, b}$ and Ahmed M. Mohammed ${ }^{a}$ \\ ${ }^{a}$ Department of Chemistry, Addis Ababa University, Addis Ababa, Ethiopia \\ ${ }^{b}$ Institute of Organic Chemistry and Biochemistry, Czech Academy of Sciences, Prague, Czech Republic
}

\author{
Email: sene3095@gmail.com (T. B. D.)
}

\begin{abstract}
The level of carbon dioxide $\left(\mathrm{CO}_{2}\right)$ in the atmosphere is increasing at an alarming rate. As a result, it has become vital for chemists, environmentalists and other concerned scientists to find ways of transforming undesirable $\mathrm{CO}_{2}$ to fuels and other harmless and valuable chemicals. Among the approaches used for $\mathrm{CO}_{2}$ conversion, metal-based and metal-free catalysis are the most commonly used technologies. Although encouraging results have been obtained in electrocatalytic, photocatalytic, and photoelectrochemical $\mathrm{CO}_{2}$ reduction and hydrogenation, obtaining selective and stable catalysts at lower temperature has remained a challenge. Understanding the details of the reaction mechanisms is also another challenge. Computational studies using density functional theory (DFT) have potentials in alleviating such challenges. In this minireview, we highlight the promising areas where DFT can contribute and the challenges related to such computational studies aiming to show the already available opportunities for further improvements in the field.
\end{abstract}

Keywords $\mathrm{CO}_{2}$ reduction, density functional theory, computational studies, catalysis

\section{Introduction}

Most of the energy demand of the world is fulfilled by fossil fuels. $\mathrm{CO}_{2}$, which is the most oxidized form of carbon, is the final combustion product of carbon-based fuels. Exhaustive consumption of fossil fuels results in excessive $\mathrm{CO}_{2}$ emission, which causes climate change and global warming. This is becoming a challenge for our planet. Due to this, world leaders set an objective of net decarbonization of human activities before 2100 during their December 2015 meeting in Paris. ${ }^{[1]}$ Although there are natural systems for the consumption of $\mathrm{CO}_{2}$ (photosynthesis and related sinks), the ratio between the amount of $\mathrm{CO}_{2}$ produced and that fixed is increasing from time to time.

Green plants use $\mathrm{CO}_{2}$ and $\mathrm{H}_{2} \mathrm{O}$ for photosynthesis to convert solar energy into chemical energy and store it in the form of glucose and release $\mathrm{O}_{2}$ to the environment. ${ }^{[2,3]}$ In addition to this, scientists have designed ways of reducing $\mathrm{CO}_{2}$ from the environment. ${ }^{[2,4-11]}$ For example, reducing the excessive $\mathrm{CO}_{2}$ emitted to the environment into fuels and valuable chemicals is among the techniques used to improve the ecological environment and decrease global warming. ${ }^{[2,10,12-18]}$ Mimicking photosynthesis through catalysis is also becoming promising. This gives an opportunity, which provides alternative fuel sources. Moreover, there are various efforts and approaches being performed on the conversion of $\mathrm{CO}_{2}$ to valuable organic compounds. ${ }^{[2,10,12-18]}$ Some of them are found to be very promising, whereas others are already in a way to get implemented in industries.

There are reviews about the current trends and progresses of $\mathrm{CO}_{2}$ conversion into fuels and valuable chemicals. ${ }^{[2,11,14,19-28]}$ Even though the research field is very important in many aspects, understanding the reaction mechanisms and availability of efficient catalysts is still a big challenge. In this aspect, there are promising developments regarding the contribution of theoretical/computational studies. ${ }^{[12,29-32]} \mathrm{A}$ highlight about such developments, opportunities and challenges is important. Specifically, computational studies can contribute tremendously in homogeneous and heterogeneous catalysis, metal-free catalysis, reaction mechanisms, product selectivity, stability, and design of new catalysts (Figure 1). Therefore, this minireview is intended to scratch the field and thereby promote further developments in this research area. We would like to note that there are varieties of computational approaches to study different reactions. Since the majority of researchers are employing density functional theory as a tool to study $\mathrm{CO}_{2}$ reduction, we discuss only about DFT in this minireview.

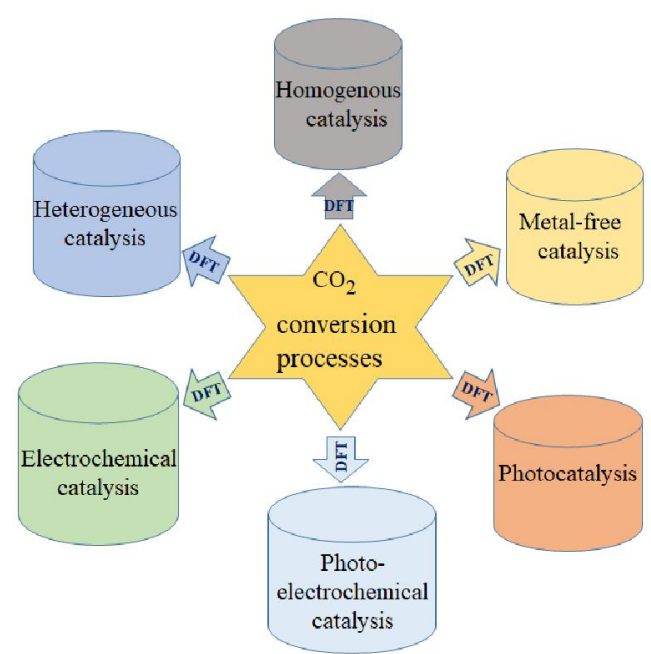

Figure 1 The different $\mathrm{CO}_{2}$ reduction technologies, in which computational approaches can contribute.

Most of the $\mathrm{CO}_{2}$ reactions are thermodynamically unfavorable. ${ }^{[18]}$ The direct one-electron reduction to the radical $\mathrm{CO}_{2}{ }^{-}$, for example, is very energy intensive $(\Delta G=257 \mathrm{~kJ} / \mathrm{mol}) .{ }^{[17]}$ Upon transfer of one electron, the structure of $\mathrm{CO}_{2}$ changes from linear to bent configuration, which results in irreversible reduction. In this aspect, proton coupled multiple-electron $\mathrm{CO}_{2}$ 
reduction is easier than single electron reduction, although they are kinetically challenging. ${ }^{[15,28,33]}$ It is possible to overcome such limitations through the use of catalysts. To drive the multielectron-multi proton reduction of carbon dioxide to the desired way, supplementing energy to the system is essential to promote electrons at the required reaction negative potentials. Among the methods that can be used to supplement energy to the system are: (1) sacrificial compounds which can be consumed to directly reduce $\mathrm{CO}_{2}$ if the oxidation potential of the compound is negative enough to react with $\mathrm{CO}_{2},(2)$ light which can be used to pump energy into the catalytic system, and (3) an electrode which can be used either as catalytic surface or to transfer electrons at the desired potential to the catalytic species. $^{[10,14,21,23,25,27,34-36]}$

When carbon dioxide is used with another reactant that has a higher Gibbs free energy, the reaction becomes thermodynamically more feasible. As the reaction rate is directly dependent on activation energy, that the starting materials shall cross over, when the reaction proceeds, a catalyst is needed to decrease the activation energy. The catalysts offer specific sites to activate $\mathrm{CO}_{2}$. Each activation method shows characteristic reactivity of $\mathrm{CO}_{2}$ and products due to the unique form of activated $\mathrm{CO}_{2}$ during its reaction. Such processes can be studied using computational methods, which give an opportunity for better understanding of the reaction mechanisms, designing new catalysts with tailored properties, and providing extra information during the interpretation of the experimental results.

In the next sections, we highlight three different $\mathrm{CO}_{2}$ reduction technologies together with the promising opportunities from computational studies, as well as few examples where DFT was used either as the main tool of study and as a synergistic approach together with the experimental techniques.

\section{Electrocatalytic $\mathrm{CO}_{2}$ Conversion}

Electrocatalytic approaches can be used to convert $\mathrm{CO}_{2}$ into $\mathrm{CO}$, formaldehyde, formic acid, methanol and methane with the help of various electrocatalysts. ${ }^{[37]}$ The electrocatalysts can be homogeneous or heterogeneous systems. A homogeneous catalyst is dissolved in an electrolyte and get reduced at the surface of an electrode, which itself is inserted to the desired electrochemical reaction medium. Macrocyclic ligands complexed with $\mathrm{Re}, \mathrm{Ru}, \mathrm{Pd}, \mathrm{Fe}, \mathrm{Ni}, \mathrm{Mn}$ are among the many metal complexes used in homogeneous catalysis for electrocatalytic $\mathrm{CO}_{2}$ reduction in non-aqueous electrolytes. ${ }^{[18]}$

Heterogeneous electrocatalysts are commonly metals, or metal-based solids such as oxides, sulfides, and phosphides. $^{[16,21,38-39]}$ They have different exposed crystal facets and surface nanostructures. In most cases, these structures are more disordered than their molecular counterparts and therefore more difficult to study. Due to their complex surface chemistry, they are able to promote more complex reactions. ${ }^{[27]}$ Heterogeneous electrochemical reduction of $\mathrm{CO}_{2}$ occurs at electrode-electrolyte interfaces. Figure 2 illustrates the processes taking place during the electrochemical $\mathrm{CO}_{2}$ reduction reaction.

Both the homogenous and heterogeneous catalytic reactions can be modeled using computational techniques. ${ }^{[12,29-31,40]}$ Three steps are mainly considered when modeling these catalytic processes: (1) chemical adsorption of $\mathrm{CO}_{2}$ on the surface of a catalyst (cathode), (2) electron transfer and/or proton migration to break $\mathrm{C}-\mathrm{O}$ bonds and/or form $\mathrm{C}-\mathrm{H}$ bonds, and (3) rearrangement of product species followed by desorption from electrode surface and diffusion into the electrolyte (Figure 2). There are catalysts made from organometallics, metals, alloys, and carbon nanostructures. Among all these, only copper

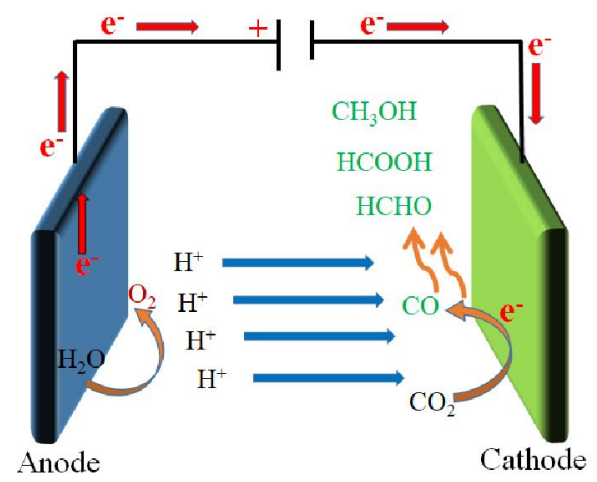

Figure 2 The electrochemical $\mathrm{CO}_{2}$ reduction process and the possible products generated in an electrochemical reaction cell. At the anode water splits, and at the cathode $\mathrm{CO}_{2}$ conversion takes place. Details of such processes are briefly discussed in Ref. [7, 17, 41-44].

exhibits selectivity towards the formation of hydrocarbons and multi-carbon oxygenates at fairly high efficiencies, whereas most others favor production of carbon monoxide or formate. ${ }^{[9]}$ In such cases, computational studies (specially DFT) can tremendously contribute in identifying and designing new electrocatalysts with tailored properties to increase the efficiency of electrocatalytic $\mathrm{CO}_{2}$ reduction reactions leading to specific compounds.

\section{Metal-Free Catalytic $\mathrm{CO}_{2}$ Conversion}

Besides metal complexes, metal free catalysts are also other options used for $\mathrm{CO}_{2}$ reduction. ${ }^{[9,41,45]}$ Metal-free electrocatalysts exhibit better advantages than heterogeneous metal-based electrocatalysts. The main reasons for this are environmental friendliness, rich sources of the metal-free catalysts, low overpotential, good stability, high surface area, and excellent electrical conductivity. For example, $\mathrm{N}$-doped carbon nano-fibers and $\mathrm{N}$-doped carbon nanotubes have been satisfactorily used for $\mathrm{CO}_{2}$ reduction to $\mathrm{CO}^{[46]} \mathrm{N}$-doped fullerene derivative metal-free catalysts have also been used for electrochemical reduction of $\mathrm{CO}_{2}$ to formate. It has also been reported that $\mathrm{N}$-doped graphene quantum dots catalyze the electrochemical reduction of $\mathrm{CO}_{2}$ into multi-carbon hydrocarbons and oxygenates at high Faradaic efficiencies, high current densities and low overpotentials. ${ }^{[9]}$ Even though it exhibited very poor catalytic property, graphene oxide (GO) has also been reported to show catalytic activity for $\mathrm{CO}_{2}$ reduction. ${ }^{[42]}$ Although the catalytic activity of pure carbon materials for the electrochemical reduction of $\mathrm{CO}_{2}$ is mostly neglected, heteroatom-doped carbon electrocatalysts exhibit excellent catalytic activity. ${ }^{[9,47]}$ This is another interesting area of study, which can further be improved and understood with the help of computational studies.

Analyzing the efficiency of heteroatom-doped materials using computational studies has many advantages: (1) designing and screening stable structures of the heteroatom-doped materials, (2) analyzing the reaction mechanisms of $\mathrm{CO}_{2}$ reduction that lead to the formation of different valuable compounds, and (3) saving time and resources for the basic research being conducted in this area.

\section{Photocatalytic $\mathrm{CO}_{2}$ Conversion}

Thermodynamic barriers are common in reactions between $\mathrm{CO}_{2}$ and other molecules such as water and hydrogen. ${ }^{[19]}$ For such a case, light is used as energy input to overcome the thermodynamic barriers, and hence photocatalytic $\mathrm{CO}_{2}$ conversion. ${ }^{[3,36,48]}$ Among the various photo-catalysts are $\mathrm{TiO}_{2}$, 
$\mathrm{ZnO}, \mathrm{Fe}_{2} \mathrm{O}_{3}, \mathrm{ZrO}_{2}, \mathrm{SnO}_{2}, \mathrm{BiWO}_{3}, \mathrm{CdS}, \mathrm{ZnS}, \mathrm{GaN}$, and $\mathrm{SiC} .^{[24,35,49]}$ While the overall reaction may be energetically unfavorable, each of the redox half-reaction (reduction and oxidation) can be energetically favorable.

In photocatalytic $\mathrm{CO}_{2}$ reduction systems with water, both photo-reduction of $\mathrm{CO}_{2}$ and photo-oxidation of $\mathrm{H}_{2} \mathrm{O}$ occur simultaneously under sunlight irradiation. ${ }^{[3,17,19,20,22,26,27,49]}$ Figure 3 illustrates the basic principles of $\mathrm{CO}_{2}$ reduction processes. ${ }^{[3]}$ These processes are highly endothermic than water splitting owing to the positive $\Delta G^{\circ}$ values. Moreover, $\mathrm{CO}_{2}$ reduction is thermodynamically unfavorable particularly for hydrocarbon fuels such as $\mathrm{CH}_{3} \mathrm{OH}$ and $\mathrm{CH}_{4}$. Even though computational studies are promising to study the details of such reactions and simultaneously show possible ways of alleviating the problem, ${ }^{[8,50-52]}$ there are very few studies concerning the photocatalytic conversion of $\mathrm{CO}_{2}$ into value added chemicals. Particularly, time-dependent density functional theory (TD-DFT) has a potential to study the reaction mechanisms and activity of the catalysts taking place in the excited state. A schematic representation and DFT mechanistic study of the $\mathrm{CO}_{2}$ reduction reaction to methane and $\mathrm{CO}$ is presented in Figure 3.
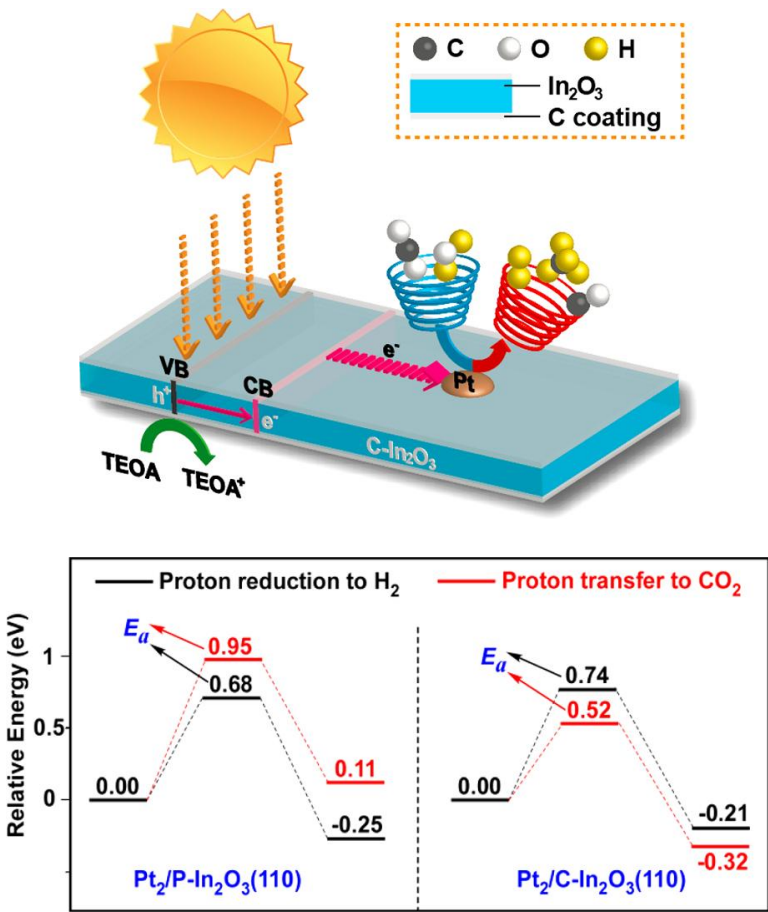

Figure 3 Top: Schematic representation of the mechanism of the photocatalytic $\mathrm{CO}_{2}$ reduction with water on $\mathrm{Pt} / \mathrm{C}-\mathrm{In}_{2} \mathrm{O}_{3}$, with triethanolamine (TEOA) as the electron donor to bind with the hole. Bottom: DFT-calculated relative energy profiles for the proton reduction into $\mathrm{H}_{2}$ and proton transfer to an $\mathrm{O}$ atom of $\mathrm{CO}_{2}$ on $\mathrm{Pt}_{2} / \mathrm{PIn}_{2} \mathrm{O}_{3}(110)$ and $\mathrm{Pt}_{2} / \mathrm{C}-\mathrm{In}_{2} \mathrm{O}_{3}(110)$. Note that the proton $\left(\mathrm{H}^{+}\right)$transfer to the adsorbed $\mathrm{CO}_{2}$ on $\mathrm{Pt}_{2} / \mathrm{C}-\mathrm{In}_{2} \mathrm{O}_{3}(110)$ is easier than the $\mathrm{H}_{2}$ formation, whereas the $\mathrm{H}_{2}$ formation that takes place on $\mathrm{Pt}_{2} / \mathrm{P}-\mathrm{In}_{2} \mathrm{O}_{3}(110)$ is preferred over the proton transfer to the adsorbed $\mathrm{CO}_{2}$. Reprinted with permission from Ref. [3]. Copyright @ 2018, American Chemical Society.

\section{Contributions from DFT Calculations}

Computational investigation of catalytic $\mathrm{CO}_{2}$ reduction into different value-added products has attracted much attention of researchers. The design of metal-free and metal-containing catalysts can be facilitated by accurate computational simulations based on DFT calculations. ${ }^{[32,53]}$ The catalytic activity is determined from the binding energies of the reaction interme- diates bound to the catalyst active sites in their lowest energy conformation.

A highly selective catalyst for $\mathrm{CO}_{2}$ reduction to $\mathrm{CO}$, for instance, requires the capability of immobilizing $\mathrm{COOH}$ but weak binding of $\mathrm{CO}$ at the same time. For $\mathrm{CO}_{2}$ reduction to $\mathrm{CO}$, one needs to find an optimal ${ }^{*} \mathrm{COOH}$ binding strength, which is being not too weak and not too strong in terms of thermodynamic activity. Therefore, an ideal $\mathrm{CO}_{2}$ reduction catalyst for the two-electron reduction of $\mathrm{CO}_{2}$ to $\mathrm{CO}$ should have a ${ }^{*} \mathrm{COOH}$ binding energy of around $0.12 \mathrm{eV}$ at zero applied potential and acidic condition. In this arena, there are reports discussing the computational study of electrochemical $\mathrm{CO}_{2}$ reduction at transition metal electrodes. ${ }^{[29]}$ Some catalysts perform well for the process and some others not. Such kind of catalysts can be modified and even new ones can be designed with the help of computational techniques.

In some cases, a stand-alone experimental investigation struggles to give clear picture of the reaction. A synergistic application of experimental and computational techniques gives full story about the study. In such a case, there are studies, which implemented DFT for the study of $\mathrm{CO}_{2}$ reduction. ${ }^{[8,40,52,54,55]}$ For example, experimentally, $\mathrm{Fe}$ is an ineffectual $\mathrm{CO}_{2}$ electroreduction catalyst, despite being active for thermal $\mathrm{CO} / \mathrm{CO}_{2}$ reduction catalysis. At reduction overpotentials, the hydrogen evolution reaction dominates and the production of hydrocarbons is minimal to none. A DFT analysis of low-coverage reaction intermediate energies for the paths to produce $\mathrm{CH}_{4}$ and $\mathrm{CH}_{3} \mathrm{OH}$ from $\mathrm{CO}_{2}$ suggests that $\mathrm{Fe}$ could be more active than $\mathrm{Cu}$, which is good metallic catalyst to show selectivity towards hydrocarbon formation. ${ }^{[31]}$

The key factor underlying the catalytic mechanism is that the interaction between adsorbate $\left(\mathrm{CO}_{2}\right)$ and metal surfaces are enormously determined by the d-band levels of the catalyst itself. By adjusting the location of the d-band centers, the bonding strength of adsorbed intermediates $\left({ }^{*} \mathrm{COOH},{ }^{*} \mathrm{CO}\right.$, etc.) and Gibbs free energy $(\Delta G)$ consumed in rate-determining steps would be optimized to enhance the catalytic performance. Hence, in order to achieve satisfying activities of metallic catalysts, various approaches can be implemented to adjust the d-band levels through, for instance, particle size optimization, surface modification, and exposure of different crystal planes/active sites. ${ }^{[32]}$ Such adjustments and modifications can be studied and screened out using computational studies. Even the simplest concept of the conformational change of $\mathrm{CO}_{2}$ when it is adsorbed onto the surface of the catalyst (linear to bent) can be easily modeled using DFT calculations (Figure 4). ${ }^{[32]}$

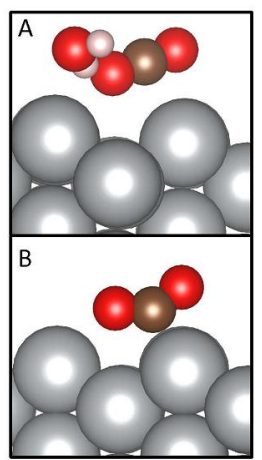

Figure 4 (A) The distorted adsorbed $\mathrm{CO}_{2}\left({ }^{*} \mathrm{CO}_{2}\right)$ which has a bond angle of $178^{\circ}$ and bond lengths of $1.17 \AA$ (hydrogen-bonded oxygen) and $1.16 \AA$. (B) The adsorbed $\mathrm{CO}_{2}$ anion $\left({ }^{*} \mathrm{CO}_{2}{ }^{\mathrm{D}}\right)$ species, which has a bond angle of $140^{\circ}$ and bond lengths of $1.24 \AA$ (left oxygen) and $1.22 \AA$ (right oxygen). Reprinted with permission from Ref. [32]. Copyright @ 2017 , National Academy of Sciences. 


\section{Catalytic $\mathrm{CO}_{2}$ Hydrogenation as a General Example}

Catalytic hydrogenation of $\mathrm{CO}_{2}$ using $\mathrm{H}_{2}$ is becoming a potential path for the sustainable production of lower olefins, higher hydrocarbons, formic acid, methanol, and higher alcohols (Figure 5). ${ }^{[10,11,13,16,21,34,56,57]}$ Hydrogen is a reducing agent and a high-energy material that can be used for $\mathrm{CO}_{2}$ transformation. To achieve this, $\mathrm{H}_{2}$ needs to be dissociated into the atomic adsorbed $\mathrm{H}^{*}$ onto the active sites, followed by the reduction of the activated $\mathrm{CO}_{2}$ which transforms to the desired value added products. ${ }^{[58]}$ Such processes can proceed via the use of either heterogeneous or homogenous catalysts as discussed above.

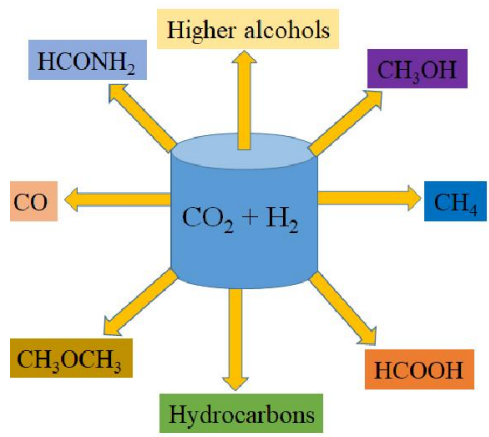

Figure 5 Conversion of $\mathrm{CO}_{2}$ to chemicals and fuels through hydrogenation. Details of such conversions are briefly discussed in Ref. [7, 10, 20, 21, 23-25, 34, 35, 59].

Many types of catalysts have been investigated for the hydrogenation of $\mathrm{CO}_{2} \cdot{ }^{[7,23,43,51,60-62]}$ Among them, $\mathrm{Cu}$ is the main active catalyst together with different modifiers like $\mathrm{Zn}, \mathrm{Zr}, \mathrm{Ce}$, $\mathrm{Al}, \mathrm{Si}, \mathrm{V}, \mathrm{Ti}, \mathrm{Ga}, \mathrm{B}, \mathrm{Cr}$. To further increase the activity and stability of $\mathrm{Cu} / \mathrm{ZnO}$ catalyst, $\mathrm{Ga}_{2} \mathrm{O}_{3}$ and $\mathrm{SiO}_{2}$ are used as stabilizers and promoters. ${ }^{[31]}$ In such cases, the adsorption and dissociation of hydrogen occur on the $\mathrm{Cu}$ site, while the adsorption of $\mathrm{CO}_{2}$ as bicarbonate takes place on the $\mathrm{ZnO}$ site (Figure 2). Copper interacts very poorly with $\mathrm{CO}_{2}$, and zinc is necessary to enhance binding of intermediates and hence accelerates the conversion. The atomic hydrogen then transfers from the surface of $\mathrm{Cu}$ onto the surface of $\mathrm{ZnO}$ and stepwise hydrogenates the adsorbed carbon containing species to methanol. ${ }^{[7,23,51,60-62]}$

In addition to Cu-based catalysts, several other materials exhibit activity in $\mathrm{CO}_{2}$ hydrogenation. ${ }^{[7,23,51,60-62]}$ Some catalysts show strong selectivity. For instance, when the reaction is carried out over a $\mathrm{Pt} / \mathrm{Cu} / \mathrm{SiO}_{2}$ catalyst, formaldehyde is the main product rather than methanol. Hydrogen is chemisorbed on the surface of platinum, and then diffuses to the surface of copper. The migrated surface hydrogen then promotes the formation of formaldehyde. This is an implication for the product selectivity of the $\mathrm{CO}_{2}$ reduction technologies.

Computational studies are capable of identifying catalysts, which can be selectively used for specific products. DFT studies also play important roles in identifying feasible reaction pathways of $\mathrm{CO}_{2}$ reduction towards specific products. ${ }^{[12]}$ For instance, a DFT study on $\mathrm{CO}_{2}$ reduction, which takes place on the defected anatase $\mathrm{TiO}_{2}$ (101) surface, showed that oxygen vacancies play a critical role in promoting the reaction, as compared to the pristine surface. ${ }^{[51]}$ Such vacancies help $\mathrm{CO}_{2}$ binding, activation, and dissociation and thereby stabilize other reaction intermediates. ${ }^{[51]}$

\section{Methanol Production as a Specific Example}

Methanol is a well-known liquid used for hydrogen storage and as sustainable building block for olefin and liquid fuel production. ${ }^{[63-65]}$ Methanol based hydrogen storage is safer than formic acid, because methanol has no acidity. Among the cataIytic methanol production technologies, direct $\mathrm{CO}_{2}$ hydrogenation $\left(3 \mathrm{H}_{2}+\mathrm{CO}_{2} \rightarrow \mathrm{CH}_{3} \mathrm{OH}+\mathrm{H}_{2} \mathrm{O}\right)$ and formic acid hydrogenation $\left(\mathrm{HCOOH}+2 \mathrm{H}_{2} \rightarrow \mathrm{CH}_{3} \mathrm{OH}+\mathrm{H}_{2} \mathrm{O}\right)$ are the most widely applied methods. ${ }^{[7,23,38,60,62]}$ Although direct hydrogenation of $\mathrm{CO}_{2}$ to methanol is the most straightforward and desirable process, conversion to methanol is potentially equilibrium-limited at elevated reaction temperatures since the reaction is exothermic process. To increase the efficiency of methanol synthesis, some researchers developed methods for methanol production via intermediate products formation, such as carbonate, formate, and urea from $\mathrm{CO}_{2}$.

Density functional theory calculations have been widely used for such reactions. For instance, calculations performed on the conversion of $\mathrm{CO}_{2}$ to methanol on the surface of $\mathrm{Fe}(100)$ clearly indicated feasible reaction mechanisms (Figure 6). ${ }^{[31]}$ Such studies can shed further light on the experiments as well as find better and feasible reaction pathways, which can simultaneously reduce $\mathrm{CO}_{2}$ and produce methanol.

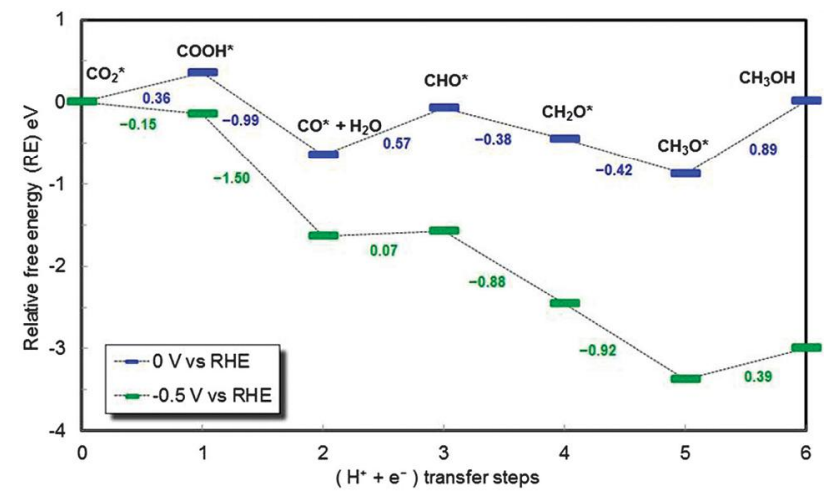

Figure 6 Relative free energy diagram for reduction of $\mathrm{CO}_{2}$ to $\mathrm{CH}_{3} \mathrm{OH}$ on $\mathrm{Fe}(100)$ at 0 ( blue) and -0.5 (green) V-RHE. Numbers indicate the relative energy change of each reduction step. Reprinted with permission from Ref. [31]. Copyright (C) 2014, Royal Society of Chemistry.

\section{Challenges of $\mathrm{CO}_{2}$ Conversion and DFT}

Even though it is a very promising area of research, $\mathrm{CO}_{2}$ reduction is challenging and needs various improvements. ${ }^{[2,11,14,19-28]}$ The challenge starts from the catalysts. As it is evident, some of the desirable properties of efficient heterogeneous catalysts are: high surface area, single site structure, mobility of charge carriers, and product selectivity. Light absorption, as well as efficient and long lifetime of charge separation are also additional required properties for photocatalysts. The low photocatalytic efficiency, low response to sunlight, inefficient electron transport between reduction and oxidation catalysts, and high recombination rate of photogenerated species are the major difficulties responsible for the current considerably low rate of productivity. Another drawback is the short lifetimes of one-electron-reduced species and the photo-excited states. ${ }^{[14,20-21,23,25-27,34-36,43,49,59,66]}$

Product selectivity of $\mathrm{CO}_{2}$ reduction is related to the reaction conditions and pathways. Different parameters, such as electrocatalyst, applied potential, electrolyte, $\mathrm{pH}$ value, temperature, and pressure play important roles to the product selectivity of $\mathrm{CO}_{2}$ reduction. ${ }^{[14,20-23,25-27,34-36,43,49,59,66]}$ For instance, Ir/Ru oxide could efficiently convert $\mathrm{CO}_{2}$ into different valuable organic molecules (ethanol as the major product; methanol, acetone and acetaldehyde as the minor products in the liquid phase). ${ }^{[43]}$ Therefore, product selectivity is also one of the biggest challenges. ${ }^{[7,22,43,62]}$ 
The pathways for $\mathrm{CO}_{2}$ reduction are also affected by external reaction conditions, like temperature and pressure, $\mathrm{pH}$ value and solvent composition. ${ }^{[67]}$ High temperature reduces the solubility of $\mathrm{CO}_{2}$ in solvent. Selectivity of products can be altered by the reaction temperature due to the different adsorption ability of products. High-pressure can increase the $\mathrm{CO}_{2}$ concentration in solution by increasing the solubility of $\mathrm{CO}_{2}$. Hence, all these challenges and factors need further research to improve the current status of $\mathrm{CO}_{2}$ reduction. ${ }^{[2,11,14,19-28]}$

Moreover, the efficiency of some conversion approaches is still not high enough for practical applications. Typically, the efficiency of some photocatalytic or photo-electrochemical processes for $\mathrm{CO}_{2}$ conversion is even lower than that in natural photosynthesis. The activity and stability/durability of $\mathrm{CO}_{2}$ conversion methods have not been fully understood. Catalysts may lose their catalytic activity. The catalyst degradation mechanisms are not well understood. There are still obstacles for scalable, long-term production, low-efficiency, high cost and space waste in existing $\mathrm{CO}_{2}$ conversion technologies. Technological advancements are still not sufficient for wide practical applications.

Although significant researches into the reaction mechanisms of $\mathrm{CO}_{2}$ conversion have been investigated, many processes for $\mathrm{CO}_{2}$ conversion to fuels and chemicals are still unclear. In most of these aspects, state-of-the-art computational approaches (specifically DFT, but not limited to) can contribute considerably in improving the $\mathrm{CO}_{2}$ reduction status by designing new effective catalysts with tailored properties, analyzing the reaction mechanisms, and finding possible solutions based on the calculated results.

The computational studies also face challenges. One of the most concerning challenges is finding appropriate program package for the study. There are very popular and powerful program packages, which are commercial and inaccessible for the majority of researchers working in the field of $\mathrm{CO}_{2}$ reduction. Choosing user friendly and efficient method and program package is another challenge. In this aspect, besides its limitations, DFT is now the preferable method being used for $\mathrm{CO}_{2}$ reduction reactions, and provides important insights for the research. ${ }^{[8,12,32,52-55]}$ Treating solvent effects during the calculations is also challenging. The use of explicit solvent models could give better results compared to the use of implicit solvent models. However, the former solvent model is a challenge since it requires high-performance computing facilities. The later has been used for computational study of $\mathrm{CO}_{2}$ reduction reaction mechanisms, which appears to give satisfactory results. ${ }^{[54-55,68]}$ When dealing with catalytic reactions involving inner transition metals, the treatment of relativistic effects is also necessary, which is another challenge. There are possibilities to at least treat scalar-relativistic effects, like the use of effective core potentials (ECPs). ${ }^{[8,30]}$

Since $\mathrm{CO}_{2}$ is a typically weakly adsorbed molecule, missing of the weak long-range interactions may also cause non-negligible errors during the calculations. Some strategies include the correction of long-range interactions, such as constructing nonlocal functional and introducing empirical corrections. Besides all these, the current computational methods are able to capture the basic science behind $\mathrm{CO}_{2}$ reduction.

\section{Future Perspectives and Conclusions}

The high stability of $\mathrm{CO}_{2}$, low selectivity of catalysts, instability of catalytic structures at different conditions, complex mechanisms and dynamics of catalyzed transformations are the challenges in $\mathrm{CO}_{2}$ conversion into fuels and valuable chemicals. $^{[2,11,14,19-28]}$ Complicated electrochemical systems such as surface structure of electrode, charge distribution at the solid-liquid interface, and solvation effect of electrolyte makes difficult to accurately consider all the aspects in computational studies. Treatment of electrode-electrolyte interface is too expensive to consider dynamic explicit solvation environment with numerous solvent molecules, whereas the implicit model can lose hydrogen bond and other important interactions, in which the solvent participates. One available method is to place few explicit solvent molecules in the implicit solvent environment which requires understanding of interface using faster and more efficient methods. Therefore, more research is required in these areas to get clear picture of the reaction.

$\mathrm{CO}_{2}$ conversion to fuels has low efficiency due to high stability and multi-electron reaction. As discussed above, low stability, low efficiency and low product selectivity are the main limitations. The performance of the catalysts can be increased by selecting catalysts having low band gap, implying that prior design of the reaction mechanisms using computational studies is very valuable. Such studies are also very important for interpreting experimental results.

In general, catalytic $\mathrm{CO}_{2}$ conversion into fuels and valuable chemicals is a promising way to solve environmental issues in the future. Researchers carry out systematic and careful experimental studies to design efficient, inexpensive and nontoxic catalysts. Homogeneous catalysts are good for $\mathrm{CO}_{2}$ reduction in their reactivity compared to heterogeneous catalysts, but it is difficult to separate the products. Metal-free catalysts are low cost, stable, selective and highly active compared to heterogeneous catalysts.

To sum it up, the major promising areas where DFT calculations contribute in improving $\mathrm{CO}_{2}$ reduction reactions are:

(1) Designing efficient catalysts derived from varieties of metals as well as metal-free molecular systems.

(2) Testing the newly designed catalysts with tailored properties by analyzing the reaction mechanisms.

(3) Determining the main active sites during the catalytic processes.

(4) Investigating and proposing efficient catalytic reaction mechanisms and pathways.

\section{Acknowledgement}

T. B. D. would like to acknowledge the Institute of Organic Chemistry and Biochemistry of the Czech Academy of Sciences, and the European Regional Development Fund; OP RDE; Project: "IOCB Mobility" No. CZ.02.2.69/0.0/0.0/16_027/ 0008477".

\section{Author Contributions}

The manuscript was written through contributions of all authors. All authors have given approval to the final version of the manuscript.

\section{References}

[1] Walsh, B.; Ciais, P.; Janssens, I. A.; Peñuelas, J.; Riahi, K.; Rydzak, F.; van Vuuren, D. P.; Obersteiner, M. Nat. Commun. 2017, 8, 14856.

[2] Benson, E. E.; Kubiak, C. P.; Sathrum, A. J.; Smieja, J. M. Chem. Soc. Rev. 2009, 38, 89.

[3] Pan, Y.-X.; You, O.; Xin, S.; Li, O.; Fu, G.; Cui, Z.; Men, Y.-L.; Cao, F.-F.; Yu, O.-H.; Goodenough, O. B. J. Am. Chem. Soc. 2018, 139, 4123.

[4] Jang, J.; Jeon, B. W.; Kim, Y. H., Sci. Rep. 2018, 8, 7211.

[5] Paulussen, S.; Verheyde, B.; Tu, X.; De Bie, C.; Martens, T.; Petrovic, D.; Bogaerts, A.; Sels, B. Plasma Sourc. Sci. Technol. 2010, 19, 034015

[6] Ganesh, I., Renew. Sust. Energ. Rev. 2014, 31, 221.

[7] Reithmeier, R.; Bruckmeier, C.; Rieger, B. Catalysts 2012, 2, 544. 
[8] Zhu, C.-Y.; Zhang, Y.-Q.; Liao, R.-Z.; Xia, W.; Hu, J.-C.; Wu, J.; Liu, H.; Wang, F. Dalton Trans. 2018, 47, 13142.

[9] Wu, J.; Ma, S.; Sun, J.; Gold, J. I.; Tiwary, C.; Kim, B.; Zhu, L.; Chopra, N.; Odeh, I. N.; Vajtai, R.; Yu, A. Z.; Luo, R.; Lou, J.; Ding, G.; Kenis, P. J. A.; Ajayan, P. M. Nat. Commun. 2016, 7, 13869.

[10] Su, X.; Xu, J.; Liang, B.; Duan, H.; Hou, B.; Huang, Y. J. Energy Chem. 2016, 25, 553.

[11] Wang, W.; Wang, S.; Ma, X.; Gong, J. Chem. Soc. Rev. 2011, 40, 3703.

[12] Hussain, J.; Jónsson, H.; Skúlason, E. ACS Catal. 2018, 8, 5240.

[13] Wu, J.; Wen, C.; Zou, X.; Jimenez, J.; Sun, J.; Yujian Xia; Rodrigues, M.-T. F.; Vinod, S.; Jun Zhong, N. C.; Odeh, I. N.; Ding, G.; Lauterbach, J.; Ajayan, P. M. ACS Catal. 2017, 7, 4497.

[14] Grice, K. A. Coord. Chem. Rev. 2017, 336, 78.

[15] Wei, J.; Ge, Q.; Yao, R.; Wen, Z.; Fang, C.; Guo, L.; Xu, H.; Sun, J. Nat. Commun. 2017, 8, 1.

[16] Qin, Z.; Zhou, Y.; Jiang, Y.; Liu, Z.; Ji, H. INTECH 2017, 58.

[17] Zhang, N.; Long, R.; Gao, C.; Xiong, Y. Sci. China Mater. 2018, 61, 771.

[18] Aresta, M.; Dibenedetto, A.; Quaranta, E. J. Catal. 2016, 343, 2.

[19] Lingampalli, S. R.; Ayyub, M. M.; Rao, C. N. R. ACS Omega 2017, 2, 2740.

[20] Ye, S.; Wang, R.; Wu, M. Z.; Yuan, Y. P., Appl. Surf. Sci. 2015, 358, 15.

[21] Danga, S.; Yanga, H.; Gao, P.; Wang, H.; Li, X.; Wei, W.; Sun, Y. Catal. Today 2019, 330, 61.

[22] Kuramochi, Y.; Ishitani, O. Coord. Chem. Rev. 2018, 373, 333.

[23] Onishi, N.; Laurenczy, G.; Beller, M.; Himeda, Y. Coord. Chem. Rev. 2018, 373, 317.

[24] Wen, Y.; Zhang, J.; Wu, X.-T.; Zhu, Q. L. Coord. Chem. Rev. 2018, 376, 248.

[25] Su, T.-m.; Qin, Z.-z.; Ji, H.-b.; Jiang, Y.-x.; Huang, G. Environ. Chem. Lett. 2016, 14, 99.

[26] Zhao, H.; Pan, F.; Li, Y. J. Materiomics 2017, 3, 17.

[27] Zeng, S. Nanotechnology 2018, 29, 1.

[28] Ramos-Fernandez, E. V.; Rothenberg, G. RSC Adv. 2014, 4, 16456.

[29] Hussain, J.; Skúlason, E.; Jónsson, H. Procedia Comput. Sci. 2015, $51,1865$.

[30] Rodriguez, M. M.; Peng, X.; Liu, L.; Li, Y.; Andino, J. M. J. Phys. Chem. C 2012, 116, 19755.

[31] Bernstein, N. J.; Akhade, S. A.; Janik, M. J. Phys. Chem. Chem. Phys. 2014, 16, 13708.

[32] Singh, M. R.; Goodpaster, J. D.; Weber, A. Z.; Head-Gordon, M.; Bell, A. T. Proc. Natl. Acad. Sci. U.S.A. 2017, 114, E8812.

[33] Pannwitz, A.; Wenger, O. S., Chem. Commun. 2019, 55, 4004.

[34] Saeidi, S.; Amina, N. A. S.; Rahimpour, M. R. J. $\mathrm{CO}_{2}$ Util. 2014, 5, 66.

[35] Wang, W.; Soulis, J.; Yang, J.; Biswas, P. Aerosol Air Qual. Res. 2014, 14, 533.

[36] Ismail, A. A. Sol. Energy Mater. Sol. Cells. 2014, 128, 85.

[37] Larrazabal, G. O.; Martin, A. J.; J., P.-R. J. Phys. Chem. Lett. 2017, 8, 3933.

[38] Liu, M.; Yi, Y.; Wang, L.; Guo, H.; Bogaerts, A. Catalysts 2019, 9 , 1.

[39] Al-Omari, A. A.; Nguyen, H. L. Molecules 2018, 23, 1.
[40] Wang, H.; Jia, C.; Yang, J.; Zhao, X.; Li, Y.; Sun, H.; Fan, W. RSC Adv. 2015, 5, 77973.

[41] Duan, X.; Xu, J.; Wei, Z.; Ma, J.; Guo, S.; Wang, S.; Liu, H.; Dou, S. Adv. Mater. 2017, 29, 1701784.

[42] Yuan, J.; Zhi, W.-Y.; Liu, L.; Yang, M.-P.; Wang, H.; Lu, J.-X. Electrochim. Acta 2018, 282, 694.

[43] Tursunov, O.; Kustov, A. IFP Energies nouvelles 2017, 72.

[44] Zhang, W.; Hu, Y.; Ma, L.; Zhu, G.; Wang, Y.; Xue, X.; Chen, R.; Yang, S.; Jin, Z. Adv. Sci. 2018, 5, 1.

[45] Xie, J.; Zhao, X.; Wu, M.; Li, Q.; Wang, Y.; Yao, J. Angew. Chem. Int. Ed. 2018, 57, 9640.

[46] Sun, X.; Kang, X.; Zhu, Q.; Jun Ma, G. Y.; Liu, Z.; Han, B. Chem. Sci. 2016, 7, 2883.

[47] Chen, Z.; Mou, K.; Yao, S.; Liu, L. J. Mater. Chem. A 2018, 6, 11236.

[48] Takeda, H.; Ohashi, K.; Sekine, A.; Ishitani, O. J. Am. Chem. Soc. 2016, 138, 4354.

[49] Ola, O.; Maroto-Valer, M. J. Photochem. Photobiol. C: Photochem. Rev. 2015, 24, 16.

[50] Poudyal, S.; Laursen, S. Catal. Sci. Technol. 2019, 9, 1048.

[51] Liu, J.-Y.; Gong, X.-Q.; Alexandrova, A. N. J. Phys. Chem. C 2019, 123, 3505.

[52] Wang, Y.; Tian, Y.; Yan, L.; Su, Z. J. Phys. Chem. C 2018, 122, 7712.

[53] Cui, C.; Wang, H.; Zhu, X.; Han, J.; Ge, Q. Sci. China Chem. 2015, $58,607$.

[54] Zhang, C.; Lu, Y.; Zhao, R.; Menberu, W.; Guo, J.; Wang, Z.-X. Chem. Commun. 2018, 54, 10870

[55] Shen, J.; Kolb, M. J.; Göttle, A. J.; Koper, M. T. M. J. Phys. Chem. C 2016, 120, 15714.

[56] Gnanamania, M. K.; Hamdeh, H. H.; Shafera, W. D.; Hoppsa, S. D.; Davisa, B. H. Appl. Catal., A-Gen. 2018, 564, 243.

[57] Dietz, L.; Piccinin, S.; Maestri, M. J. Phys. Chem. C 2015, 119 4959.

[58] Zhong, H.; Yao, G.; Cui, X.; Yan, P.; Wang, X.; Jin, F. Chem. Eng. J. 2019, 357421.

[59] Wang, W. N. KONA Powder Part. J. 2019, 36, 201.

[60] Gomes, C. D. N.; Blondiaux, E.; Thu, P.; Cantat, T. Chem. Eur. J. 2014, 20, 7098.

[61] Lonis, F.; Tola, V.; Cau, G. Fuel 2019, 246, 500.

[62] Yang, D.; Zhu, Q.; Chen, C.; Liu, H.; Liu, Z.; Zhao, Z.; Zhang, X.; Liu, S.; Han, B. Nat. Commun. 2019, 10, 1.

[63] Li, Y.; Cui, X.; Dong, K.; Junge, K.; Beller, M. ACS Catal. 2017, 7, 1077.

[64] Liu, Q.; Wu, L.; Jackstell, R.; Beller, M. Nat. Commun. 2015, 6 , 5933.

[65] Mastalir, M.; Pittenauer, E.; Allmaier, G.; Kirchner, K. J. Am. Chem Soc. 2017, 139, 8812.

[66] Singh, S. B. Green Chem. Technol. Lett. 2016, 2, 206.

[67] Song, J. T.; Song, H.; Oh, J. Catalysts 2019, 224, 1

[68] Yamada, H. J. Phys. Chem. B 2016, 120, 10563.

Received August 10, 2019 Accepted September 6, 2019 